\title{
Effectiveness of Off Pump CABG in Impaired Left Ventricular Function
}

\author{
Ihab Moursi', Mohamed Abd al aal ${ }^{1}$
}

${ }^{1)}$ Zagazig University Hospital, Department of Cardiothoracic Surgery, Faculty of Human Medicine, Egypt

\section{Introduction}

In most of the cardiac centers, the off-pump coronary artery bypass (OPCAB) surgery is an accepted mode of revascularization. The surgery without cardiopulmonary bypass has obvious advantages in high-risk patients. Severe left ventricular (LV) dysfunction is a known independent factor of operative mortality in patients with coronary artery bypass grafting $(\mathrm{CABG})$ surgery. ${ }^{(1-2)}$ the technique of off-pump (OPCAB) has both theoretical and practical advantages. Critical patients with impaired left ventricular (LV) function who need coronary artery bypass grafting (CABG) have an augmented risk of Perioperative mortality and morbidity. ${ }^{(3,4,5)}$ The aim of this single-center retrospective study was to compare early and short-term outcomes after conventional $(\mathrm{CCAB})$ in patients and off-pump beating heart coronary artery bypass grafting (OPCAB) in patients have ejection fraction (EF) equal to or less than $35 \%$., with regards to intensive care unit (ICU) stay, hospital course, the use of intra-aortic balloon pump support, the need of inotropic support, blood loss and renal function deterioration.

\section{Patients and Methods}

Preoperative assessment and data collection, all data according to the legal Customs and traditions of Saudi Arabia with granted informed consent were collected retrospectively, patients demographics data, risk factors, operative information and postoperative outcome data from our database system at Prince Sultan Cardiac Center - Al Hofuf- KSA which is maintained in our center to document all cardiac surgical activity. 150 patients with impaired LV function based on a recorded ejection fraction (EF) equal to or less than $35 \%$ subjected to isolated CABG between September 2010 to July 2013 were collected and statistically analyzed. 60 $(40 \%)$ patients underwent CABG with off-pump beating technique (group1) and $90(60 \%)$ patients with the conventional technique (group2). For each group, the clinical, angiographic characteristics, the operative and early and short-term outcome data were compared. We exclude Patients subjected to combined surgery, redo surgery, emergency procedures, big heart, a left ventricular aneurysm or aortic surgery. The off-pump beating and conventional surgery were on the basis of the 
preference of the surgeons carrying out the operations. Identification of impaired LV function was based on either the preoperative echocardiography or thallium-201 myocardial scintigraphy that were performed to measure the left ventricular function and to assess myocardial viability. This viability study was done when indicated in some patients according to their clinical, echocardiography and coronary LV angiography data. Euro SCORE was comparable in terms of surgical risk stratification. Outcome measures for this study included ICU and hospital stay, postoperative complications including bleeding, arrhythmias, and renal complications. Duration of inotropic support, the length of mechanical ventilation, hospital mortality and length of ICU and hospital stay were recorded.

Hospital mortality was defined as death after the procedure before patient's discharge regardless of the duration of hospitalization. Patients who died after discharge from hospital but within 30 days after the procedure were also considered as hospital mortality. Postoperative blood loss was defined as total chest tube drainage. Respiratory failure was defined as prolonged ventilator therapy ( $>72$ hours) or need for re-intubation or tracheostomy. Renal complications included acute renal failure needs hemodialysis with creatinine more than $200 \mathrm{mmol} / \mathrm{L}$. Surgical Techniques off-Pump beating (OPCAB) Coronary revascularization: All patients were anesthetized with the same standard manner either OPCAB or Conventional. All patients were hemodynamically monitored by both radial and femoral arterial lines for systemic pressures and Swan- Ganz a catheter for pulmonary artery pressure. Patient required $5 \mathrm{mi}$ crograms $/ \mathrm{kg} / \mathrm{min}$ of Dopamine infusion to support the heart during the procedure, which was discontinued on completion of graft placements.

The median sternotomy is the method of approach for all surgical procedures. Standard technique was used for harvesting of left internal mammary artery (LIMA) and Saphenous vein. Cell saver was used during these procedures. By using $3 \mathrm{mg} / \mathrm{kg}$ Heparin to achieve activated clotting time more than 350 seconds. It should repeat each 20 -minutes the activated clotting time to check this. Complete revascularization was the goal in all cases and we performed bypass grafting to all.

Graftable vessels in which the myocardium was vi- able. The distal anastomosis for left internal thoracic artery graft was constructed with 7-0 polypropylene continuous suture and for the saphenous vein grafts and radial artery grafts 7-0 polypropylene suture was used. All proximal anastomoses of the radial artery, grafts were constructed using 7-0 polypropylene suture and the saphenous vein grafts were constructed using 6-0 poly propylene suture.

Stabilization of the heart to achieve the target coronary artery by Octopus (Medtronic Inc, USA). A humidified carbon dioxide blower/mister (Medtronic Inc, USA) was used to clarify the anastomotic site while constructing the distal anastomosis. Posterior and lateral target coronary arteries were accessed by deep pericardial traction sutures and/or with the use of Starfish cardiac positioner (Medtronic Inc., USA). A mean systemic arterial pressure was maintained around 65-70 $\mathrm{mm}$ of $\mathrm{Hg}$ throughout the procedure. An intra-coronary shunt was used whenever it was possible while constructing the coronary anastomosis for all the vessels.

The strategies of coronary artery grafting were to graft left internal thoracic artery to left anterior descending artery first, followed by either obtuse marginal arteries or right coronary artery whichever was stenosis is critical. The target vessel was occluded proximally using a 4-0 polytetrafluoroethylene suture passed twice beneath the artery to prevent direct contact between the suture and the anterior coronary wall. Techniques of conventional CABG: After full systemic heparinization to achieve activated clotting time level of at least 400 seconds, CPB was instituted in a usual manner. After aortic cross-clamp, myocardial protection is achieved by blood Cardioplegia in an antegrade fashion combined with systemic hypothermia $28-30^{\circ} \mathrm{C}$. Cardioplegia was repeated each 20 minutes and after every distal anastomosis. Distal anastomoses were completed first, then the proximal anastomoses using the single aortic cross-clamp or partial clamp. The release of Aortic cross-clamp, the weaning of CPB, and reversal of heparin was done in a standard manner. The intra-aortic balloon pump was inserted in patients with hemodynamic instability.

\section{Statistical Analysis:}

Using a statistical software package (Graph Pad In 
Stat ${ }^{\circledR}$ version 3.00 for Windows, Graph Pad Software Inc., San Diego, California, USA). Data is presented as mean (SD), numbers or ratio as needed. Data were analyzed using the student t-test; Variables that are not normally distributed were compared using the MannWhitney test. Nonparametric data were analyzed using Chi-square test or the Fisher exact test as appropriate. Two-tail $\mathrm{P}$ values $<0.05$ were considered significant.

\section{Results:}

Between September 2010 to July 2013,150 patients with impaired LV function based on a recorded ejection fraction (EF) equal to or less than $35 \%$ subjected to isolated $\mathrm{CABG}$ were collected and statistically analyzed. $60(40 \%)$ patients underwent CABG with off-pump beating technique (group1) and $90(60 \%)$ patients with the conventional technique (group2). The mean Euro SCORE for OPCAB patients was $3.45 \pm 1.8$ and for onpump patients was $3.30 \pm 1.4(\mathrm{p}=0.36)$ and both groups were comparable in terms of surgical risk stratification.

(Table 1), shows the comparison between the demographic patient's data with no significant differences and the preoperative variables in the two groups. (Table 1) shows that Group 2 had higher incidences of diabetes Mellitus, hypertension, congestive heart failure and smoking history with no significant differences except for renal insufficiency (P- value 0.008).

(Table 2), shows Operative data, group 1, had less operative time due to cardiopulmonary bypass time in group 2 with a high significant difference. There is no significant differences concerning the graftable vessels and rate of complete revascularization. (Table3) shows the postoperative data, we did not find a significant differences concerning the reopening for bleeding, stroke, atrial fibrillation, in-hospital mortality and total chest drainage although it was less with OPCAB group. Perioperative Intra-aortic balloon pump (IABP) support was higher in $\mathrm{CCAB}$ group (12 patients' vs $4 \mathrm{OPCAB}$ patients: $\mathrm{P}<0.05$ ).

The indication of intra-aortic balloon pump was hemodynamic instability as high pulmonary artery pressure, or hypotension and usage of moderate or higher doses of inotropic support was also higher in the conventional group $(p<0.005)$. There is significance dif- ferences between the two group concerning,the hours of ventilation time was $7.2 \pm 6.3$ group1vs $10.1 \pm 7.2$ group2 $(\mathrm{p}<0.05)$. There is more deterioration of renal function in group 2 patient (renal failure was 7 patients $(7.8 \%)$ in group 2 vs 1 patient $(1.7 \%)(p<0.02)$. Group 2 patients had longer intensive care unit stay and hospital stay with significant differences than group 1 . There is no significant differences regarding the in hospital mortality between the two groups.

In the short-term follow up period ( 6 months after the date of surgery), the mean EF\% had improvement with statistical significance from $30 \% \pm 2.7$ to $40.0 \% \pm$ 2.0 in group 1 and from $31.8 \% \pm 3.0$ to $39 \% \pm 2.3$ in group 2. The functional class improved coincide with improvement of EF\%. The mean NYHA class had significant improvement related to the preoperative period in both groups, in group 1 from $3.4 \pm 0.5$ to $1.9 \pm .7$, vs $3.3 \pm 0.7$ to $2.0 \pm .2$ in the other group, but in all the postoperative short-term follow up period, there is no statistically significant difference between the two groups.

\section{Discussion:}

The definition of severe left ventricular dysfunction definition is not clear. The choice of ejection fraction $<35 \%$ as others defined the severe LV dysfunction although other several authors defined severe LV dysfunction as ejection fraction (EF) $<30 \%(1,6)$ The number of patients with end stage ischemic cardiomyopathy increased, that leads to increase the incidence to operate on patients have severely impaired left ventricular function for coronary revascularization. The challenge is the management of patient impaired LV function due to ischemic heart disease. Coronary artery bypass grafting has been considered as a high risk surgical procedure. ${ }^{(2)}$

In the past decade due to good outcome the OP$\mathrm{CAB}$ techniques, it was becoming popular..$^{(7,8,9-10)}$ It is noticed by many non-randomized sophisticated statistical methods that the OPCAB technique has lower incidence of re-exploration for bleeding, stroke, prolonged ventilation and acute renal failure. ${ }^{(11,12)} \mathrm{OPCAB}$ in-hospital mortality in our study was $3.3 \%$ which was comparable to other published series $(6.1 \% ; 7 \%, 6.5 \%$ and $4.4 \%{ }^{(13,14,9,15)}$ respectively. Complete revascularization depends on the suitability of diseased coronary arteries 
Table 1. Preoperative Data

\begin{tabular}{|l|c|c|c|}
\hline Characteristic & $\begin{array}{c}\text { off-Pump Beating- } \\
\text { Heart (OPCAB) } \\
(\mathbf{n}=60)\end{array}$ & $\begin{array}{c}\text { Conventional } \\
\text { CABG } \\
(\mathbf{n}=90)\end{array}$ & p Value \\
\hline Age (years) & $62.0 \pm 6.4$ & $59.2 \pm 7.5$ & NS \\
\hline $\begin{array}{l}\text { Sex } \\
\text { Male }\end{array}$ Female & $32(53.3 \%)$ & $48(53.3 \%)$ & NS \\
\hline Mean LVEF\% & $28(46.7 \%)$ & $42(46.7 \%)$ & NS \\
\hline Diabetes mellitus & $30 \% \pm 2.7$ & $31.8 \% \pm 3.0$ & NS \\
\hline Smoking & $48(80 \%)$ & $68(75.6 \%)$ & NS \\
\hline Hypertension & $14(23.3 \%)$ & $22(24.4 \%)$ & NS \\
\hline Cerebrovascular disease & $50(83.3 \%)$ & $77(85.6 \%)$ & NS \\
\hline Renal insufficiency & $4(6.7 \%)$ & $5(5.6 \%)$ & NS \\
\hline Peripheral vascular disease & $16(26.6 \%)$ & $13(14.4 \%)$ & 0.008 \\
\hline $\begin{array}{l}\text { Chronic obstructive pulmonary } \\
\text { disease (COPD) }\end{array}$ & $5(8.3 \%)$ & $8(8.9 \%)$ & NS \\
\hline Congestive heart failure & $2(3.3 \%)$ & $4(4.4 \%)$ & NS \\
\hline NYHA class & $7(11.7 \%)$ & $10(11.1 \%)$ & NS \\
\hline LVEF: left ventricular ejection fraction; NYHA: New York Heart Association, NS. Non-significant & NS \\
\hline
\end{tabular}

Table 2. Operative variables of patients on both groups.

\begin{tabular}{|c|c|c|c|}
\hline Characteristice & $\begin{array}{l}\text { off-Pump BeatingHeart } \\
\text { (OPCAB) }(n=60)\end{array}$ & $\begin{array}{l}\text { Conventional } \\
\text { CABG (n 90)) }\end{array}$ & p Value \\
\hline Operation time (min) & $230.5 \pm 58.9$ & $339.2 \pm 79.1$ & $<0.0001$ \\
\hline $\begin{array}{l}\text { Cardiopulmonary by- } \\
\text { pass time (min) }\end{array}$ & - & $110.3 \pm 45.6$ & - \\
\hline $\begin{array}{l}\text { No. of bypassed dis- } \\
\text { eased vessels }\end{array}$ & & & \\
\hline One & 6 & 7 & NS \\
\hline Two & 27 & 31 & NS \\
\hline Three & 26 & 50 & NS \\
\hline Four & 1 & 2 & NS \\
\hline
\end{tabular}


to be graftable. To reach the targeted vessels, the heart should be elevated. For left anterior descending artery and diagonal branches need light elevation which does not affect the hemodynamics. For the obtuse marginals, posterior descending artery and posterolateral ventricular branches need more elevation of ventricle which affect the coronary blood flow especially the circumflex artery. ${ }^{(16)}$

We noticed this hemodynamic instability in patients grafted for marginal branches especially if the target area is proximal, ramus intermedius which needs many manipulations to decrease it as more deep pericardial suture and tilting the operating table in Trendelenburg position with right tilt. In four cases the insertion of Intra-aortic balloon pump support is mandatory to stabilize the hemodynamics. We noticed that there is no significant difference statistically concerning the number of grafts between the two groups (OPCAB vs CCBG) in comparison to other authors. ${ }^{(9,17)}$ In this study there is no significant difference between the two groups concerning the incidence of atrial fibrillation which is coincide with other results. ${ }^{(14,15)}$ There is significant difference statistically regarding the reduction of use of Intra-aortic balloon pump support that coincide with other authors. ${ }^{(13,14,18)}$

Also there is significant reduction in the ICU and hospital stay with OPCAB group that coincide with other authors. ${ }^{(19,20)}$ The pre-existing renal dysfunction get worse, in patients do CCABG (group 2) with impaired left ventricular function $(p<0.02)$. It is proved that left ventricular end systolic volume index (LVESVI) is an important predictor for short and long term functional improvement. ${ }^{(21)}$ The LVESVI of $100 \mathrm{ml} /$ $\mathrm{m} 2$ or less, is associated with favorable outcome and recovery of the LV., but the EF\% value has no statistically significant predictor of long-term outcome, so a low EF did not differentiate between hibernation and infarction as the cause of poor contractile function. During short-term follow-up in this study, LVEF in both groups was improved and there is improvement in functional class correlated with improvement of $\mathrm{EF} \%$. But in all the postoperative short-term follow up period, there is no statistically significant difference between the two groups.

\section{Limitations and recommendations of study:}

We recommend further studies to see the long term outcomes, studies based on the LV. Dimension as LV dilation and extent of scars ${ }^{(22)}$ and studies based on classification of Low EF\% on symptomatic basis (associated with angina or associated with heart failure or both).

\section{In Conclusion:}

Off pump CABG can be performed safely and effectively in critical patients with impaired left ventricular (LV) function. The postoperative morbidity and mortality was less in Off-pump group compared to conventional technique with more renal preservation in cases of impaired renal function. 


\section{References}

1. Trachiotis GD, Weintraub WS, Johnston TS. Jones EL, Guyton RA, Craver JM. Coronary artery bypass grafting in patients with advance left ventricular dysfunction. Ann Thorac Surg 1998; 66: 1632-39.

2. Alderman EL, Fisher LD, Litwin P, et al. Results of coronary artery bypass surgery in patients with poor left ventricular function (CASS). Circulation 1983; 68: 785-95.

3. Milano CA, White WD, Smith LR, et al. Coronary artery bypass grafting in patients with severely depressed ventricular function. Ann Thorac Surg 1993; 56: 483-93.

4. Christakis GT, Weisel RD, Fremes SE, et al. Coronary artery bypass grafting in patients with poor ventricular function. J Thorac Cardiovasc Surg 1992; 103: 1083-92.

5. Zubiate P, Kay JH, Mendez AM. Myocardial revascularization for the patients with drastic impairment of function of the left ventricle. J Thorac Cardiovasc Surg 1977; 73: 84-6.

6. Hirose H, Amano A, Takanashi S, Takahashi A. Coronary artery bypass grafting for patients with poor left ventricular function. Asian Cardiovasc Thorac Ann 2003; 11: 23-27.

7. Sajja LR, Mannam G, Sompalli S, et al. Does multivessel off-pump coronary artery bypass grafting reduce postoperative morbidity compared to on-pump CABG? Ind J Thorac Cardiovasc Surg 2004; 20: 173-77.

8. Stamou SC, Jablonski KA, Hill PC, Bafi As, Boyce SW, Corso PJ. Coronary revascularization without cardiopulmonary bypass versus the conventional approach in high-risk patients. Ann Thorac Surg 2005; 79: $552-57$.

9. Arom KV, Flavin TF, Emery RW, Kshettry VR, Petersen RJ, Janey PA. Is low ejection fraction safe for off-pump coronary bypass operation? Ann Thorac Surg 2000; 70: 1021-25.

10. Stamou SC, Corso PJ. Coronary revascularization without cardiopulmonary bypass in high-risk patients: a route to the future. Ann Thorac Surg 2001; 71: 1056-61.

11. Plomondon ME, Cleveland JC, Jr Ludwig ST, et al. Off-pump coronary artery bypass grafting is associated with improved riskadjusted outcomes. Ann Thorac Surg 2001; 72: 114-19.

12. Cleveland JC Jr, Shroyer AL, Chen AY, Peterson E, Grover FL. Offpump coronary artery bypass grafting decreases risk adjusted mortality and morbidity. Ann Thorac Surg 2001; 72: 1282-89.

13. Ascione R, Narayan P, Rogers C, Lim KH, Capoun R, Angeline GD. Early and midterm clinical outcome in patients with severe left ventricular dysfunction undergoing coronary artery surgery. Ann Thorac Surg 2003; 76: 793-99.

14. Darwazah AK, Abu Sham 'a RA, Hussein E, Hawri MH, Ismail H. Myocardial revascularization in patients with low ejection fraction $=35 \%$ : Effect of pump technique on early morbidity and mortality J Card Surg 2006; 21: 22-27.

15. Tugtekin SM, Gulielmos V, Cichon R, et al. Off-pump surgery for anterior vessels in patients with severe dysfunction of the left ventricle. Ann Thorac Surg 2000; 70:1034-36.

16. Grundeman PF, Borst C, Van Herwaaden JA, Mansvel Beck HJ, Jansen EW. Hemodynamic changes during displacement of the beating heart by Utrecht Octopus method. Ann Thorac Surg 1997; 63: S88-92.

17. Chang W, Denton TA, Fontana GP, et al. Off-pump coronary surgery: effect on early mortality and stroke. J Thorac Cardiovasc Surg 2002; 124: 313-20.

18. Sajja LR, Mannam G, Chakravarthi RM, et al. Coronary artery bypass grafting with or without cardiopulmonary bypass in patients with nondialysis dependent renal insufficiency: a randomized study. J Thorac Cardiovasc Surg 2007; 133: 378-88.

19. Yadava OP, Prakash A, Kundu A, Yadava M.Coronary artery bypass grafting in women--is OPCAB mandatory?: Indian Heart J. 2011 SepOct;63(5):425-8.

20. Yu L, Gu T1, Shi E, Wang C, Fang Q, Yu Y, Zhao X, Qian C. : Offpump versus on-pump coronary artery bypass surgery in patients with triple-vessel disease and enlarged ventricles. Ann Saudi Med. 2014 May-Jun;34(3):222-8

21. Soliman Hamad MA, Peels K, Van Straten A, Van Zundert A, Schonberger J. Coronary artery bypass surgery in patients with impaired left ventricular function Predictors of hospital outcome. Acta Anaesthesiol Belg 2007; 58:37-44.

22. Carr JA, Haithcock BE, Paone G, Bernabei AF, Silverman NA. Longterm outcome after coronary artery bypass grafting in patients with severe left ventricular dusfunction. Ann thorac Surg 2002; 74:1531-6.

Received: $12 / 01 / 2016$

Accepted: 22/02/2016

Published: 15/03/2016

Disclosure and conflicts of interest:

Conflicts of interest were not reported.

\section{Corresponding author:}

Dr. Ihab Moursi

Mail: ihabmoursi@hotmail.com 